\title{
Prevalence of Cigarette Smoking and Associated Factors Among Adolescents in Eastern Ethiopia, 2020
}

\author{
Abdurahman Kedir Roble (D) \\ Mohamed Omar Osman (iD) ${ }^{2}$ \\ Om Parkash Lathwal (iD ${ }^{2}$ \\ Abdirashid Abdi Aden ${ }^{3}$ \\ 'Department of Midwifery, College of \\ Medicine and Health Science, Jigjiga \\ University, Jigjiga, Ethiopia; ${ }^{2}$ Department \\ of Public Health, College of Medicine and \\ Health Science, Jigjiga University, Jigjiga, \\ Ethiopia; ${ }^{3}$ Primary Health Care and \\ Health Extension Program Directorate \\ Office, Somali Regional Health Bureau, \\ Jigjiga, Ethiopia
}

Background: Cigarette smoking is one of the leading causes of preventable morbidity and mortality globally, and it is accountable for many causes of premature deaths. Despite the negative consequences of cigarette smoking, studies to identify factors associated with cigarette smoking are scanty and little is known about this practice in the Somali region so far, so this study aimed to assess the prevalence of cigarette smoking and associated factors among adolescents in the Gode, eastern Ethiopia 2020.

Methods: A community-based cross-sectional study design was employed among 341 adolescents in the Godey administration of the Somali Region, Eastern Ethiopia from July to August 2020. A systematic sampling technique was used to select study participants. Data were collected using a pretested interviewer administered questionnaire. The collected data were entered with Epi-Data version 3.1 and exported to SPSS version 22 software for statistical analysis. Multivariable logistic regression analyses were done to identify the true effect of predictor variables on the outcome variable after controlling for possible confounders. Statistical significance was declared at a p-value $<0.05$.

Results: Over all, the prevalence of current cigarette smoking among adolescents was found to be $21.1 \%$ (95\% CI: (16.7-25.5). Having smoker parents [AOR $=2.57,95 \% \mathrm{CI}$ : (1.32-5.02)], whose friends smoke cigarette $[\mathrm{AOR}=4.78,95 \% \mathrm{CI}$ : $(2.12-10.76)]$, and currently chewing $k$ hat $[\mathrm{AOR}=6.01,95 \% \mathrm{CI}:(2.96-12.23)]$ were significantly associated predictors of current cigarette smoking in the final model of multivariable analysis.

Conclusion: The prevalence of cigarette smoking was relatively high in this study area. This study reported having smokers' parents, having smokers' friends and chewing khat were found to be independent predictors for cigarette smoking. Therefore, effective smoking prevention and intervention programs are required in this area.

Keywords: adolescent, tobacco, cigarettes, khat, smoking, substances

\section{Introduction}

Smoking is one of the leading causes of preventable morbidity and mortality worldwide and is responsible for millions of premature deaths. Tobacco smoke is a risk factor for cardiovascular disease, asthma, pneumonia, lung cancer, and other cancers. ${ }^{1-3}$ The World Health Assembly urges governments to reduce cigarette consumption by $30 \%$ between 2013 and 2025 and prevent 200 million deaths from smoking, but data show that one person dies from smoking every 6 seconds. According to WHO data, tobacco currently kills up to $50 \%$ of those who use it. It also reported that, an estimated 1.3 billion smokers live in low- and middle-income countries. ${ }^{4,5}$
Correspondence: Abdurahman Kedir Roble Department of Midwifery, College of Medicine and Health Science, Jigjiga University, P.O. Box 1020, Jigjiga, Ethiopia Tel +25I 910047I 30

Email kedirabdurahman I14@gmail.com; abdurahmankedirroble@jju.edu.et 
According to the latest data, it is estimated that $50 \%$ of young men and $10 \%$ of young women will become smokers, and the number of deaths due to tobacco use each year will gradually increase, reaching about 10 million within the next few decades. ${ }^{6-9}$ Cigarettes are the biggest threat in Africa. In Africa, tobacco smoke is predicted to be present in $3.46 \%$ to $36.6 \%$ of adolescents, with $7.8 \%$ to $35.5 \%$ in adolescent boys. ${ }^{7}$

In sub-Saharan Africa, there are about 84 million smokers, and more than 331 million adolescents actually live there. If no action is taken, the number of smokers in sub-Saharan Africa is expected to increase by $148 \%$ by the end of $2030 .{ }^{8}$

Adolescence is a period of self-reflection of new roles and experimenting with new experiences, so many young people are forced to smoke or take drugs as attempts that are ultimately difficult to overcome and lead to premature death. A previous study reported factors associated with cigarette smoking in adolescents include residences, parental smoking, khat chewing, peer effects, and lack of knowledge regarding the deleterious effects of smoking. ${ }^{10-13}$

The use of tobacco smoke is one of the Ethiopia's major health and socio-economic problems, especially in groups of adolescents. As reported in the 2016 Ethiopian Demographic Health Survey (EDHS), regional differences in smoking ranged from $1 \%$ in Amhara to $13 \%$ in Dire Dawa, with the highest smoking rate reported in the Somali region, which was at $18 \% .{ }^{14}$ There are few studies in Ethiopia on adolescents smoking, but there are study limitations in eastern Ethiopia, especially in the Somali region. Moreover, the previous few studies conducted in Ethiopia focused on institutions such as universities and college students.

The Somali region state of eastern Ethiopia shares cultural, ethnic, and religious ties with Eastern African nations like Somalia. Thus, this research will be input for regional governments to develop tobacco prevention strategies that are culturally, ethnically, and religiously compatible.

Therefore, this community-based study aims to identify the prevalence and determinants of smoking among adolescents residing in Gode, eastern Ethiopia.

\section{Methods and Materials Study Area and Period}

The study was conducted in the Gode City Administration of Eastern Ethiopia from July to August 2020. Gode City Administration is found in eastern Ethiopia, located
$1295 \mathrm{~km}$ east of Addis Ababa. The city has 15 urban administrative kebeles and the majority of the people living in this area are Somali in ethnicity (97\%) and Muslim in religion $(99 \%)$.

\section{Study Design}

A community-based cross-sectional study design was employed.

\section{Study Population}

All randomly selected adolescents aged $10-19$ years, who had been living in Gode for at least 6 months, were considered as the study population. Those adolescents who were seriously ill during the data collection period were excluded from the study.

\section{Sample Size Determination}

The minimum required sample size for this study was determined using a single population proportion formula. The proportion of adolescent cigarette smoke was taken from a study done in Makele, Ethiopia, which was $29.5 \%,{ }^{15}$ with an assumption of margin error of $5 \%$, a confidence interval of $95 \%$, and a non-response rate assumed to be $10 \%$.

$$
n=\frac{(\mathrm{Z} \alpha / 2)^{2} \mathrm{p}(1-\mathrm{p})}{(\mathrm{d})^{2}}
$$

where $\mathrm{n}=$ Sample size, $\mathrm{Z}=$ value corresponding to a $95 \%$ level of significance $=1.96$

$\mathrm{P}=$ proportion cigarette smoking among Mekele 29.5\%

$\mathrm{d}=$ marginal error assumed to be $5 \%$.

$$
\mathrm{n}=\frac{(1.96)^{2}(0.295 \times 0.705)}{(0.05)^{2}}=320
$$

Including $10 \%$ (Non respondents) $=$ the final sample size for this study was 352 adolescents.

\section{Sampling Technique and Procedure}

Since all kebels in Gode city administration are homogeneous, five city kebels were randomly selected from 15 kebels in Gode city administration. Hence, a preliminary assessment was conducted in each selected kebele to identify households with adolescents aged 10-19 years along with their corresponding household identification numbers. Using respective household identification numbers, frames of households containing study participants were prepared. The sample size was then distributed proportionally for 
each selected kebele based on the number of adolescents identified during the preliminary study. Lastly, adolescents were carefully chosen using systematic random sampling techniques from a frame containing a respective source of the population. A K-interval calculated from the list was 13,105 ( $\mathrm{K}$ interval $13,105 / 342=38$ ). As a result, approximately every 38 th household with adolescents was visited. Whenever more than one eligible respondent was found in the same household, only one respondent was included in the study by a lottery method.

\section{Data Collection Methods and Materials}

Face-to-face interviews were conducted using a structured and pretested questionnaire adapted and modified from Global Youth Tobacco and other relevant literature. The questionnaires were translated into the local language and it cover socio-demographic, personal, social, and family factors. The data were collected by five BSc nurses and two supervisors who were trained for two days. The data collectors interviewed the adolescents after they decided to participate in the study. The two supervisors closely supervised the quality of the data.

\section{Variables and Measurements}

In this study, the outcome of interest was current cigarettes smoking status. The current smoking status of the adolescents was measured by asking respondents "have you smoked cigarette within the last 30 days preceding the study"? Those adolescents answering "Yes" to the question are classified as current smokers, and those answering "No" are categorized as current non-smokers. ${ }^{16}$ The explanatory variable was sociodemographic factors such as: age, sex, education, occupation, and marital status. Personal and social factors like: peer influences, having friends who smoke, social media, khat chewing, alcohol drinking, any other substances used, advertisements, believe the harmfulness of tobacco. Family factors include: smokers" parents, educational level of parents, marital status of the parents, occupation of the parents, and family supervision. Believe the harmfulness of tobacco is measured using the item "Is tobacco smoking harmful to your health? 1. Definitely not. 2. Probably not. 3. Probably yes, 4 . Definitely yes". Knowing the harmfulness of tobacco. It was divided into two parts. Definitely not, and probably not coded as 2, which means it will not hurt. Probably yes, and definitely yes, in category 1 , meaning yes, tobacco is harmful to your health.

Having friends who smoke was assessed using the item "Do any of your closest friends' smoke tobacco?" 1. none of them, 2. some of them, 3. most of them, 4. all of them.
The variable was recorded as " 2 " = "none of them smoke" and the rest as " $1 "=$ "friends smoke cigarettes".

"Alcohol use was evaluated with the question, "Did you ever drink alcohol?" "Never," "one or two days in the past year," "once a month or less," "2 or 3 days a month," "1 or 2 days a week," "3 to 5 days a week," and "every day or almost every day" were the original response options. Then, it was grouped into two: 1 for ever drinking alcohol and "2" for never drinking alcohol.

Parental smoking is determined by the response to the question "Do your parents smoke? Respondents were given the following option: $1=$ none, $2=$ Both $3=$ father only, $4=$ mother only. It was further grouped into $1=$ parent smoking, 2 = parent not smoking.

"Khat chewing" was also evaluated using the item "In the last 30 days, how often did you chew Khat?". Respondents who answered "every day", "almost every day", "2-3 times a week", "once a week" and "once a month" were classified as "current Khat Chewers", whilst those who answered "I did not chew Khat" during the last 30 days were categorized as "nonchewers.

\section{Operational Definition}

Current cigarette smokers: An adolescent who smoke cigarette at least once in the last 30 days prior to data collection time. ${ }^{17}$

Adolescence: is a developmental stage of 10 to 19 years where rapid development occurs, and it is a time when young people rapidly change physically and mentally, acquire new capacities, and are faced with many new situations. ${ }^{18}$

Khat is a plant with fresh leaves and soft twigs with amphetamine like characteristics, with effects including insomnia, euphoria, decreased fatigue, and suppressed appetite when chewed. It is a perennial shrub whose leaves are chewed for its stimulant effect.

\section{Data Quality Control}

The English version's structured questionnaires were translated into Somali and then re-translated back into the English version to ensure its consistency. Then, 5\% of the questionnaires were pre-tested before conducting actual data collection in Kebele, which was not included in the study, and possible modifications were made. Data collectors, along with the supervisors, were trained for two days regarding the purpose of the study, and data 
collection procedures. Close supervision of data collectors was done on a daily basis.

\section{Data Processing and Analysis}

The data were entered into Epi-Data version 3.1 and analyzed with SPSS version 22 software. The descriptive statistics were carried out. A bivariable analysis was done to select candidates' variables for multivariable analysis, and all variables having a p-value less than 0.25 were included in the multivariable logistic regression model. The model adequacy has been checked using Hosmer and Lemeshow goodness of fitness tests. Moreover, multicollinearity was checked using the variance inflation factor (VIF) and tolerance. Finally, the strength of the associations between the outcome and independent variables was assessed using an adjusted odd ratio (AOR) with a 95\% confidence interval. A p-value $<0.05$ was used to determine the statistical association in the multivariable analysis.

\section{Ethical Consideration}

The Institutional Review Board (IRB) of Jigjiga University granted ethical approval in accordance with the Declaration of Helsinki. The Gode town administration office has authorized the study in writing. Participants were informed that participation in the study was entirely voluntary. Each participant signed an informed consent form. For participants under the age of 18, written consent from their parents or guardians was obtained. All data were anonymized during the data collection process.

\section{Results}

\section{Socio-Demographic Characteristics}

A total of 341 participants were included in the study, with the response rate of $96.9 \%$. The mean age of participants was 16.5 SD \pm 1.926 . More than half of the study participants, $171(50.1 \%)$, were in the age range of $17-19$ years. The majority of the participants, 302 (88.6\%) and 303 (88.9\%), were Somali and Muslim, respectively. In regard to the sex of the adolescents, more than two-thirds (70.3\%) of the study participants were male. Nearly half of participants, 164 (48.1\%), attended secondary school and 63 (18.5\%). Only $46(13.5 \%)$ fathers and $18(5.3 \%)$ mothers of respondents had attended college and university (Table 1).
Table I Socio Demographic Characteristic of Study Participants in Gode, Eastern Ethiopia, 2020 ( $N=34$ I)

\begin{tabular}{|c|c|c|c|}
\hline Variables & Categories & $\begin{array}{l}\text { Frequency } \\
\text { (N) }\end{array}$ & $\begin{array}{c}\text { Percentage } \\
\text { (\%) }\end{array}$ \\
\hline Age in year & $\begin{array}{l}10-13 \\
13-16 \\
17-19\end{array}$ & $\begin{array}{c}54 \\
116 \\
171\end{array}$ & $\begin{array}{l}15.8 \\
34.0 \\
50.1\end{array}$ \\
\hline Sex & $\begin{array}{l}\text { Male } \\
\text { Female }\end{array}$ & $\begin{array}{c}243 \\
98\end{array}$ & $\begin{array}{l}71.3 \\
28.7\end{array}$ \\
\hline Marital status & $\begin{array}{l}\text { Currently married } \\
\text { Not married }\end{array}$ & $\begin{array}{c}43 \\
298\end{array}$ & $\begin{array}{l}12.6 \\
87.4\end{array}$ \\
\hline Ethnicity & $\begin{array}{l}\text { Somali } \\
\text { Other }\end{array}$ & $\begin{array}{c}302 \\
39\end{array}$ & $\begin{array}{l}88.6 \\
11.4\end{array}$ \\
\hline Religion & $\begin{array}{l}\text { Muslim } \\
\text { Other }\end{array}$ & $\begin{array}{c}303 \\
38\end{array}$ & $\begin{array}{l}88.9 \\
11.1\end{array}$ \\
\hline Occupation & $\begin{array}{l}\text { Students } \\
\text { No occupation } \\
\text { Daily laborer }\end{array}$ & $\begin{array}{c}232 \\
36 \\
73\end{array}$ & $\begin{array}{l}68.0 \\
10.6 \\
21.4\end{array}$ \\
\hline $\begin{array}{l}\text { Education level } \\
\text { of participants }\end{array}$ & $\begin{array}{l}\text { Not attended formal education } \\
\text { Primary } \\
\text { Secondary } \\
\text { College and University }\end{array}$ & $\begin{array}{c}63 \\
84 \\
164 \\
30\end{array}$ & $\begin{array}{l}18.5 \\
24.6 \\
48.1 \\
8.8\end{array}$ \\
\hline $\begin{array}{l}\text { With whom you } \\
\text { live }\end{array}$ & $\begin{array}{l}\text { Family } \\
\text { Alone } \\
\text { Relatives }\end{array}$ & $\begin{array}{c}200 \\
95 \\
46\end{array}$ & $\begin{array}{l}58.7 \\
27.9 \\
13.5\end{array}$ \\
\hline $\begin{array}{l}\text { Educational level } \\
\text { of the father }\end{array}$ & $\begin{array}{l}\text { Not attended formal education } \\
\text { Primary } \\
\text { Secondary } \\
\text { College and University }\end{array}$ & $\begin{array}{l}122 \\
152 \\
21 \\
46\end{array}$ & $\begin{array}{c}35.8 \\
44.6 \\
6.2 \\
13.5\end{array}$ \\
\hline $\begin{array}{l}\text { Educational level } \\
\text { of mother }\end{array}$ & $\begin{array}{l}\text { Not attended formal education } \\
\text { Primary } \\
\text { Secondary } \\
\text { College and University }\end{array}$ & $\begin{array}{l}187 \\
112 \\
24 \\
18\end{array}$ & $\begin{array}{c}54.8 \\
32.8 \\
7.0 \\
5.3\end{array}$ \\
\hline
\end{tabular}

\section{Prevalence of Cigarette Smoking and Smoking Characteristics of the Participants}

Of 341 adolescents, 72 of them were currently smoking a cigarette, thus the prevalence of current smoking was $21.1 \%$ (95\% CI: (16.7 25.5)). In this study, the prevalence of cigarette smokers was $28.0 \%$ and $4.1 \%$ among males and females, respectively. Among nonsmokers, 28 (10.4\%) of them had previously smoked cigarettes.

The majority, 39 (54.2\%) of adolescents who smoke began smoking between the ages of 13-16, and the mean age of starting smoking was 15.75 years. The mean number of cigarettes smoked each day was 10,486 with SD 
$+/ 4.49$, and roughly $45.8 \%$ of smokers smoked in excess of 10 pieces of cigarettes daily (Table 2).

This study also found that nearly half $(47.2 \%)$ of current smokers began smoking as a result of peer pressure, whereas $22.2 \%, 18.1 \%$, and $12.5 \%$ of current cigarette smokers initiated cigarettes due to entertainment, stress relief, and experiments, respectively.

\section{Factors Associated with Cigarette Smoking (Multi-Variable Analysis)}

In this study, having a cigarette-smoking parent, an adolescent whose friend smokes cigarettes, and an adolescent who chews khat were significantly associated with current cigarette smoking.

The odds of cigarette smoking were 2.57 folds $[\mathrm{AOR}=2.57,95 \%$ CI: (1.32-5.02)] higher among adolescent whose parents smoked than their counterparts. It also found that khat chewing strongly associated predictor of current cigarette smoking. Adolescents who currently chew khat were 6.1 times more likely to smoke cigarettes than nonkhat chewers $[\mathrm{AOR}=6.01,95 \% \mathrm{CI}:(2.96-12.23)]$.

Furthermore, this study found that having a smoker friend increases the risk of cigarette smoking. Adolescents who had smoker friends were 4.78 times more likely to smoke cigarettes $[\mathrm{AOR}=4.78,95 \% \mathrm{CI}$ : (2.12-10.76)] than adolescents who had nonsmoking friends (Table 3 ).

\section{Discussion}

In this study, the overall prevalence of current cigarette smoking among adolescents in the Gode administration of Eastern Ethiopia was found to be $21.1 \%$ [95\% CI: (16.7-25.5)]. This study is nearly similar to a previous study that reported $17.2 \%$

Table 2 Smoking Characteristics of the Adolescent in Gode, Eastern Ethiopia $2020(\mathrm{~N}=72)$

\begin{tabular}{|l|l|l|l|}
\hline Variables & Categories & $\begin{array}{l}\text { Frequencies } \\
\text { (N) }\end{array}$ & $\begin{array}{l}\text { Percentage } \\
\text { (\%) }\end{array}$ \\
\hline $\begin{array}{l}\text { Age started } \\
\text { cigarette }\end{array}$ & $10-13$ & 7 & 9.7 \\
& $13-16$ & 39 & 54.2 \\
& $16-19$ & 26 & 36.1 \\
\hline $\begin{array}{l}\text { Number of } \\
\text { cigarette per day }\end{array}$ & $=<10$ pcs & 39 & 54.2 \\
\hline Length of smoking & $<1$ y year & 33 & 45.8 \\
& I-3 years & 40 & 34.7 \\
& $>3$ years & 7 & 55.6 \\
& \multicolumn{2}{|l}{} \\
\hline
\end{tabular}

of Ethiopian adolescents smoke cigarettes. ${ }^{19}$ In contrast to the previous study, this study's findings were lower than those reported from Mekele (29.5\%), Jimma (42.8\%), and Eldoret (43.8\%) of western Kenya. ${ }^{15,20,21}$ The study setting and residency could be the explanation of the disparities in prevalence. In our study, we only looked at adolescents from urban areas. This study was also found to be high when compared to previous studies done in Ethiopia's urban and rural areas $(3 \%)$, Bale $(4.6 \%)$, Shewa $(4.5 \%)$, Northwest Ethiopia (6.8\%), and Eastern Africa (9.02\%). ${ }^{22-26}$ Previous studies were conducted in academic institutions such as high schools, colleges, and universities. In addition, this study was conducted in eastern Ethiopia, where khat chewing and tobacco use are common, and our study was a population-based study that only included adolescents from the urban. This study noted that the majority of current smokers $(54.2 \%)$ began smoking between the ages of thirteen and sixteen.

In the current study, respondents whose parents smoked cigarette had higher odds of smoking cigarette as compared to their counterparts. It agrees with other studies conducted in Ethiopia, Nigeria, Gambia, Nepal, and Cambodia. ${ }^{10,19,27-29}$ According to several theories such as Social Learning Theory, Social Cognitive Theory, and Social Development Models, an adolescent learns or recalls a behavior by watching his/her parents practice it. Parents who smoke in front of their children serve as role models for their children, fostering the impression that smoking is a normal adult habit. Mentally immature children would mimic their parents' smoking habits in order to satisfy their need to be like adults. ${ }^{30-32}$ Prenatal nicotine exposure has also been shown to affect reward-related brain pathways, facilitating impulsive behaviors and, as a result, higher drug addiction rates, including for tobacco. ${ }^{33}$ This finding implies that tobacco control programs for adolescents should include parent participation.

Having friends who smoke cigarettes was also another predictor associated with current cigarette smoking. According to our data, adolescents with smoker friends were about five times more likely to be current smokers than adolescents with nonsmoker friends. This is supported by a number of studies conducted in Ethiopia, Morocco, Madagascar, Cameroon, Republic of Korea and Jordan. $^{28,34-38}$ This study lends weight to theories such as social learning theory, social cognitive theory, and social development models, which contend that adolescents adopt norms, attitudes, and actions based on the sorts of peers with whom they are socialized. Being in the proximity of other smokers is now universally regarded as 
Table 3 Factors Associated with Cigarette Smoking (Multivariable Analysis) Among Adolescent in Gode, Eastern Ethiopia, 2020 (N = $341)$

\begin{tabular}{|c|c|c|c|c|c|}
\hline \multirow[t]{2}{*}{ Variable } & \multirow[t]{2}{*}{ Categories } & \multicolumn{2}{|c|}{ Cigarette Smoke } & \multirow[t]{2}{*}{ COR 95\% Cl } & \multirow[t]{2}{*}{ AOR with $95 \% \mathrm{CI}$} \\
\hline & & Yes $\mathbf{N}(\%)$ & No N(\%) & & \\
\hline \multirow[t]{2}{*}{ Marital status } & Married & $12(27.9)$ & $3 I(72.1)$ & $1.54(0.74-3.17)$ & I.30(0.55-3.08) \\
\hline & Not married & $60(20.1)$ & $238(79.9)$ & & \\
\hline \multirow[t]{2}{*}{ Educational of the person } & No formal education & 19(30.2) & $44(69.8)$ & $1.83(0.99-3.39)$ & $1.29(0.63-2.64)$ \\
\hline & Attended formal education & $53(19.1)$ & $225(80.9)$ & I & I \\
\hline \multirow[t]{2}{*}{ Parents chew khat } & Yes & $45(29.6)$ & $107(70.4)$ & $2.52(I .48-4.3 I)$ & $1.54(0.82-2.90)$ \\
\hline & No & $27(14.3)$ & $162(85.7)$ & I & I \\
\hline \multirow[t]{2}{*}{ Have a parents who smoke Cigarette? } & Yes & $54(30.5)$ & $123(69.5)$ & $3.56(1.98-6.39)$ & $2.57(1.32-5.02)^{*}$ \\
\hline & No & $18(\mid 1.0)$ & 146(89.0) & 1 & 1 \\
\hline \multirow[t]{2}{*}{ Did you Chew khat? } & Yes & $60(36.8)$ & $103(63.2)$ & $8.06(4.14-15.70)$ & $6.01(2.96-12.23) *$ \\
\hline & No & $12(6.7)$ & 166(93.3) & I & 1 \\
\hline \multirow[t]{2}{*}{ Ever used shisha } & Yes & $25(37.9)$ & $4 I(62.1)$ & $3.01(1.69-5.49)$ & $0.59(0.24-1.44)$ \\
\hline & No & $47(17.1)$ & $228(82.9)$ & I & I \\
\hline \multirow[t]{2}{*}{ Have smoker Friends } & Yes & $44(4 I . I)$ & $63(58.9)$ & $5.12(2.96-8.92)$ & $4.78(2.12-10.76) *$ \\
\hline & No & $28(12.0)$ & $206(88.0)$ & I & 1 \\
\hline \multirow[t]{2}{*}{ Believe Smoking harm health } & Yes & $5 I(18.5)$ & $224(81.5)$ & 1 & 1 \\
\hline & No & $21(3 \mid .8)$ & $45(68.2)$ & $2.05(1.12-3.74)$ & I.73(0.85-3.55) \\
\hline \multirow[t]{2}{*}{ Have you ever drink alcohol? } & Yes & $3(42.9)$ & $4(57.1)$ & $2.88(0.63-13.17)$ & I.67(0.29-9.75) \\
\hline & No & 69(20.7) & $265(79.3)$ & 1 & 1 \\
\hline
\end{tabular}

Notes: *Significantly associated at a p-value $<0.005$. Khat is a plant with fresh leaves and soft twigs with amphetamine like characteristics, with effects including insomnia, euphoria, decreased fatigue, and suppressed appetite when chewed. It is a perennial shrub whose leaves are chewed for its stimulant effect.

a good predictor of future smoking behaviors. ${ }^{30,31}$ Social influence programs can help establish social norms that deter young people from starting to smoke, and peer education strategies can work in conjunction with other health promotion efforts to maximize their effectiveness.

The current study indicated that the odds of cigarette smoking are six folds higher among khat chewers as compared to those who do not chew khat. Similar findings were reported from studies conducted in Hawassa, Mekele and other parts of Ethiopia. ${ }^{15,39,40}$ According to Problem Behavioral Theory, which argues that adolescents who participate in one form of harmful behavior are more likely to engage in another, such as smoking cigarettes versus chewing khat. This concept is predicated on the notion that a person's connection to their environment increases the likelihood of developing problemrelated behavior. ${ }^{41}$ There is also evidence that nicotineinduced brain alterations can occasionally impact the neurological response to other substances, raising the likelihood of addiction and prolonged usage. ${ }^{42}$ This study emphasizes the necessity of a holistic intervention that targets adolescent drug use, including tobacco, khat, alcohol, and shisha. Furthermore, an estimated $47.8 \%$ of the participants included in study chewed khat, showing that it is a common habit that should be examined in tandem to decrease adolescent tobacco usage.

\section{Limitations}

This study has limitations since it did not involve adolescents from rural villages, and the data was gathered during a COVID-19 outbreak, which made data collecting difficult. Moreover, adolescents are normal deny their cigarette smoking behaviors due to social desirability bias and smoking status was not confirmed using biomarkers such nicotine levels in saliva or exhaled carbon monoxide, resulting in an underestimate of the correct prevalence of cigarette smoking. ${ }^{43}$ Furthermore, because recall biases likely exist, the 30-day timeframe for asking youth about tobacco use is employed to limit the recall bias.

\section{Conclusion}

The current study reported that $21.1 \%$ of adolescents in Gode smoke cigarettes, and this result is relatively higher as compared to some of the previous study done in 
Ethiopia. Moreover, this study reported having smokers' parents and friends and chewing khat was found to be an independent predictor for cigarette smoking.

\section{Recommendation}

Tobacco taxes should be raised, and stricter laws (and enforcement) regulating who may buy tobacco products, how and where they can be purchased should be established. Prohibiting public smoking, advertising bans, and mandatory health warnings on packs should be implemented since they are extremely beneficial. In addition, local governments recommended to apply a sales prevention policy that prohibits the sale of cigarette, khat, and other drugs to minors. Moreover, other studies in eastern Ethiopia are needed to help local communities, public health professionals, healthcare practitioners, and local governments to establish policies, education, and messaging for individuals who are at risk of smoking, as well as adolescents who wish to quit.

\section{Abbreviations}

AOR, adjusted odds ratio; CI, confidence interval; WHO, World Health Organization; IHRERC, Institutional Health Research Ethics Review Committee.

\section{Data Sharing Statement}

The datasets used for analysis are available from the corresponding author on reasonable request.

\section{Ethical Approval and Consent to Participate}

Ethical clearance was obtained from the Institutional Health Research Ethics Review Committee (IHRERC) of the College of Medicine and Sciences, Jigjiga University. Support letters were written to all Gode town administration where the study was actually conducted. The informed, voluntary, written and signed consent was obtained from each study participant. In addition, informed, voluntary, written and signed assent was also obtained from the guardians and parents adolescents aged less than 18 years. Study participants were clearly informed about their right to withdraw/refuse at any stage of the study if they did not want to participate and confidentiality of the information was assured. The data collectors interviewed the participants in separated areas. Confidentiality of information and the privacy of participants were respected. This study was conducted in accordance with the Declaration of Helsinki.

\section{Acknowledgments}

The authors thank the Institutional Health Research Ethics Review Committee coordinating office of Jigjiga University College of Medicine and Health Science and Gode city administration.

\section{Author Contributions}

All authors made a significant contribution to the work reported, whether that is in the conception, study design, execution, acquisition of data, analysis and interpretation, or in all these areas; took part in drafting, revising or critically reviewing the article; gave final approval of the version to be published; have agreed on the journal to which the article has been submitted; and agree to be accountable for all aspects of the work.

\section{Funding}

No funding was received for this study.

\section{Disclosure}

The authors report no conflicts of interest in this work.

\section{References}

1. Yamamoto Y, Kiyohara C, Suetsugu-Ogata S, Hamada N, Nakanishi Y. Biological interaction of cigarette smoking on the association between genetic polymorphisms involved in inflammation and the risk of lung cancer: a case-control study in Japan. Oncol Lett. 2017;13(5):3873-3881.

2. Wang Y, Duan H, Yang X, Guo J. Cigarette smoking and the risk of pancreatic cancer: a case-control study. Med Oncol. 2014;31(10):184.

3. Lee S, Woo H, Lee J, Oh JH, Kim J, Shin A. Cigarette smoking, alcohol consumption, and risk of colorectal cancer in South Korea: a case-control study. Alcohol. 2019;76:15-21.

4. World Health Organization. Tobacco. Available from: https://www.who. int/news-room/fact-sheets/detail/tobacco. Accessed July 26, 2021.

5. PAHO, WHO. World no tobacco day; 2010. Available from: https:// www3.paho.org/hq/index.php?option $=$ com_content\&view $=$ arti cle\&id=1310:2009-world-no-tobacco-day-2010\&Itemid= 40273\&lang=en. Accessed October 6, 2021.

6. World Health Organization. tobacco. Available from: https://www. who.int/news-room/fact-sheets/detail/tobacco. Accessed February 15, 2020.

7. World Health Organization. Tobacco control. Available from: http:// www.afro.who.int/health-topics/tobacco-control. Accessed October 6, 2021.

8. World Health Organization. Health Promotion; Capacity building and initiatives. Available from: https://www.who.int/teams/health-promotion/ tobacco-control/implementing/capacity-building. Accessed October 9, 2021

9. World Health Organization. WHO global report on trends in prevalence of tobacco use 2000-2025. Available at: https://www.who.int/ publications/i/item/who-global-report-on-trends-in-prevalence-oftobacco-use-2000-2025-third-edition. Accessed June 28, 2021.

10. Okagua J, Opara P, Alex-Hart BA. Prevalence and determinants of cigarette smoking among adolescents in secondary schools in Port Harcourt, Southern Nigeria. Int J Adolesc Med Health. 2016;28 (1):19-24. 
11. Saunders C, Geletko K. Adolescent cigarette smokers' and noncigarette smokers' use of alternative tobacco products. Nicotine Tob Res. 2012;14(8):977-985.

12. Ford A, Moodie C, MacKintosh AM, Hastings G. Adolescent perceptions of cigarette appearance. Eur J Public Health. 2014;24 (3):464-468.

13. Sargent JD, Gabrielli J, Budney A, Soneji S, Wills TA. Adolescent smoking experimentation as a predictor of daily cigarette smoking. Drug Alcohol Depend. 2017;175:55-59.

14. CSA. EDHS. Available from: http:/www.csa.gov.et/survey-report /category/352-dhs-2016?download=867:2016-ethiopian-dhs-keyfindings. Accessed February 10, 2020.

15. Eticha T, Kidane F. The prevalence of and factors associated with current smoking among college of health sciences students, Mekelle University in Northern Ethiopia. PLoS One. 2014;9(10):e111033.

16. Lodebo T, Kifle W, Gebrehiwot T, Tariku A. Prevalence of cigarette smoking and its associated factors among parents at Misrak Bedawacho District, Southern Ethiopia. Addict Prev. 2017;5(1):9.

17. Wills AG, Carey G. Adolescent peer choice and cigarette smoking: evidence of active gene-environment correlation? Twin Res Hum Genet. 2013;16(5):970-976.

18. Walker JF, Loprinzi PD. Adolescent and young adult smokers who self-identify as nonsmokers: relationship with cigarette-related withdrawal and cravings. Am J Health Promot. 2016;30(7):532-535.

19. Derege N, Sabit A, Abiot G. Prevalence and predictors of cigarette smoking among adolescent of Ethiopia. J Child Adolesc Behav. 2014;3(1):182.

20. Atwoli L, Mungla PA, Ndung'u MN, Kinoti KC, Ogot EM. Prevalence of substance use among college students in Eldoret, western Kenya. BMC Psychiatry. 2011;11(1):34.

21. Ayenew M, Kabeta T, Woldemichael K. Prevalence and factors associated with substance use among street children in Jimma town, Oromiya national regional state, Ethiopia: a community based cross-sectional study. Subst Abuse Treat Prev Policy. 2020;15(1):61.

22. Getachew S, Lewis S, Britton J, Deressa W, Fogarty AW. Prevalence and risk factors for initiating tobacco and alcohol consumption in adolescents living in urban and rural Ethiopia. Public Health. 2019;174:118-126.

23. Dida N, Kassa Y, Sirak T, Zerga E, Dessalegn T. Substance use and associated factors among preparatory school students in Bale Zone, Oromia Regional State, Southeast Ethiopia. Harm Reduct J. 2014;11:21.

24. Tezera N, Endalamaw A. Current cigarette smoking and its predictors among school-going adolescents in East Africa: a systematic review and meta-analysis. Int J Pediatr. 2019;2019:4769820.

25. Woldeamanuel BT, Anteneh LM, Yohannes YB, Aga MA. Assessment of exposure to sexually explicit materials and substance abuse among high-school adolescents in North Shewa Zone: application of logistic regression analysis. J Addict. 2020;2020:8105087.

26. Birhanu AM, Bisetegn TA, Woldeyohannes SM. High prevalence of substance use and associated factors among high school adolescents in Woreta Town, Northwest Ethiopia: multi-domain factor analysis. BMC Public Health. 2014;14:1186.
27. Jallow IK, Britton J, Langley T. Prevalence and determinants of tobacco use among young people in The Gambia. BMJ Glob Health. 2017;2(4):e000482.

28. Bhaskar RK, Sah MN, Gaurav K, et al. Prevalence and correlates of tobacco use among adolescents in the schools of Kalaiya, Nepal: a cross-sectional questionnaire based study. Tob Induc Dis. 2016;14:11.

29. Rudatsikira E, Siziya S, Muula AS. Prevalence and predictors of environmental tobacco smoke exposure among adolescents in Cambodia. Indian J Community Med. 2010;35(1):100-104.

30. Hawkins JD, Weis JG. The social development model: an integrated approach to delinquency prevention. J Prim Prev. 1985;6(2):73-97.

31. Bandura A. Social learning theory of aggression. J Commun Summer. 1978;28(3):12-29.

32. Bandura A. Human agency in social cognitive theory. Am Psychol. 1989;44(9):1175-1184.

33. Blood-Siegfried J, Rende EK. The long-term effects of prenatal nicotine exposure on neurologic development. J Midwifery Womens Health. 2010;55(2):143-152.

34. Reda AA, Moges A, Yazew B, Biadgilign S. Determinants of cigarette smoking among school adolescents in eastern Ethiopia: a cross-sectional study. Harm Reduct J. 2012;9:39.

35. Veeranki SP, Mamudu HM, John RM, Ouma AE. Prevalence and correlates of tobacco use among school-going adolescents in Madagascar. J Epidemiol Glob Health. 2015;5(3):239-247.

36. Hwang JH, Park SW. Association between peer cigarette smoking and electronic cigarette smoking among adolescent nonsmokers: a national representative survey. PLoS One. 2016;11(10):e0162557.

37. McKelvey K, Attonito J, Madhivanan P, Yi Q, Mzayek F, Maziak W. Determinants of cigarette smoking initiation in Jordanian schoolchildren: longitudinal analysis. Nicotine Tob Res. 2015;17(5):552-558.

38. Mbatchou Ngahane BH, Atangana Ekobo H, Kuaban C. Prevalence and determinants of cigarette smoking among college students: a cross-sectional study in Douala, Cameroon. Arch Public Health. 2015;73:47.

39. Bago BJ. Prevalence of cigarette smoking and its associated risk factors among students of Hawassa University, College of Medicine and Health Sciences, 2016. J Addict Res Ther. 2017;8(4)2.

40. Duko B, Melese Y, Ebrahim J. Determinants of cigarette smoking among adolescents in Ethiopia: a cross-sectional study. Tob Induc Dis. 2019;17:62.

41. Jessor R. Problem-behavior theory, psychosocial development, and adolescent problem drinking. Br J Addict. 1987;82(4):331-342.

42. Wood L, Letcher T, Winstanley M. Tobacco in Australia: facts and issues Melbourne: cancer Council Victoria; 2020.

43. Crutzen R, Göritz AS. Social desirability and self-reported health risk behaviors in web-based research: three longitudinal studies. $B M C$ Public Health. 2010;10(1):720.
Substance Abuse and Rehabilitation is an international, peerreviewed, open access journal publishing original research, case reports, editorials, reviews and commentaries on all areas of addiction and substance abuse and options for treatment and rehabilitation. The manuscript management system is completely online and includes a very quick and fair peer-review system. Visit http://www.dovepress. com/testimonials.php to read real quotes from published authors. 